\title{
Methodological studies of PIXE on biological and environmental science
}

\author{
Sha Yin ${ }^{\mathrm{a}, *}$, Gu Yingmei ${ }^{\mathrm{b}}$, Liu Guodong ${ }^{\mathrm{c}}$, Wang Anpu $^{\mathrm{d}}$, Zhang Peiqun ${ }^{\mathrm{a}}$, Zhu Jieqing ${ }^{\mathrm{b}}$, \\ Shi Jian ${ }^{\mathrm{a}}$, Yang Shulan ${ }^{\mathrm{d}}$, Liu Pingsheng ${ }^{\mathrm{a}}$, Li Xiaolin ${ }^{\mathrm{b}}$ \\ ${ }^{a}$ Institute of High Energy Physics (IHEP), Academia Sinica, P.O. Box 2732, Beijing 100080, China \\ ${ }^{\mathrm{b}}$ Institute of Nuclear Research, Academia Sinica, P.O. Box 800-204, Shanghai 201800, China \\ ${ }^{\mathrm{c}}$ Institute of Radiation Medicine, Chinese Academy of Medical Science, P.O. Box 71, Tianjin, China \\ ${ }^{\mathrm{d}}$ Research Center for Eco-Environmental Sciences, Academia Sinica, P.O. Box 2871, Beijing 100085, China
}

\begin{abstract}
The Van de Graaff Facility at IHEP is mainly used for PIXE research work especially on biologicial and environmental science. The sensitivities and the number of analyzed trace elements were improved greatly using special absorbers for bone and whole blood samples. Quite good results were obtained for different biomedical research work.

Several methods for preparing samples of dispersed single aerosol particles used in Scanning Proton Microprobe (SPM) analysis were tested. The groups of different single aerosol particles from steel plant area were analyzed by means of SPM. The distributions of elemental contents in the group of single particles are mapped with three dimensional contour and the isometric. A new approach to study the group of different single aerosol particles for air pollution is developed in the present work.
\end{abstract}

\section{PIXE at IHEP}

The Van de Graaff accelerator at the Institute of High Energy Physics (IHEP), Academia Sinica built in 1958, is the first one in China. Five beam lines were constructed in 1994 devoted to nuclear analytical techniques. This accelerator was originally used for the research work of nuclear physics, but since the end of the seventies it has been mainly dedicated to the proton induced X-ray emission (PIXE) studies, especially on the area of biomedical and environmental science. PIXE has been accepted as an accurate and precise technique now due to its advantages of high sensitivity (0.1-1.0 ppm) for most of the elements essential to human beings, fairly good precision $(2-10 \%)$, rapidity, trace analysis, non-destructive and simultaneous multi-element analysis of exceedingly small amount of samples and the sensitivity of almost the same order of magnitude for most elements of interest [1,2]. A macro vacuum PIXE experimental arrangement was established in our laboratory ten years ago. An external beam PIXE line is being built now. Another PIXE line of positionsensitive spectrometer with high resolution is being developed for chemical state analysis.

\section{Functions of special absorbers}

\subsection{PIXE analysis of blood samples}

Leukemia is a frequently occurring malignant disease with unknown etiology. The correlation of trace elements with leukemia was studied in some papers, but the number of analyzed elements in whole blood by PIXE was often quite few [3] because of the existence of serious interference of Fe to other trace elements. An important improvement was adopted in our PIXE measurements for the whole blood samples, i.e. a funny $\mathrm{Cr}$ foil was used as an absorber placed in front of the $\mathrm{Si}(\mathrm{Li})$ detector. It was found that this arrangement was very efficient in improving the quality of the measured $\mathrm{X}$-ray spectra because of eliminating some sum peaks and escape peaks, and also greatly diminishing the influence of the large amount of iron existed in whole blood on the analysis of some other elements. The PIXE spectrum of whole blood using a funny $\mathrm{Cr}$ foil with thickness of $100 \mu \mathrm{m}$ as an absorber is shown in Fig. 1 with the comparison of the spectrum in [3]. Therefore the number of analyzed elements was greatly increased to as many as 11 , i.e. $\mathrm{Al}, \mathrm{Si}, \mathrm{P}, \mathrm{S}, \mathrm{K}, \mathrm{Ca}$, $\mathrm{Mn}, \mathrm{Fe}, \mathrm{Cu}, \mathrm{Zn}$ and $\mathrm{Rb}$. A fairly good result of the correlation of trace elements in whole blood with acute leukemia was obtained $[4,5]$. The results showed that the

\footnotetext{
* Corresponding author.
} 

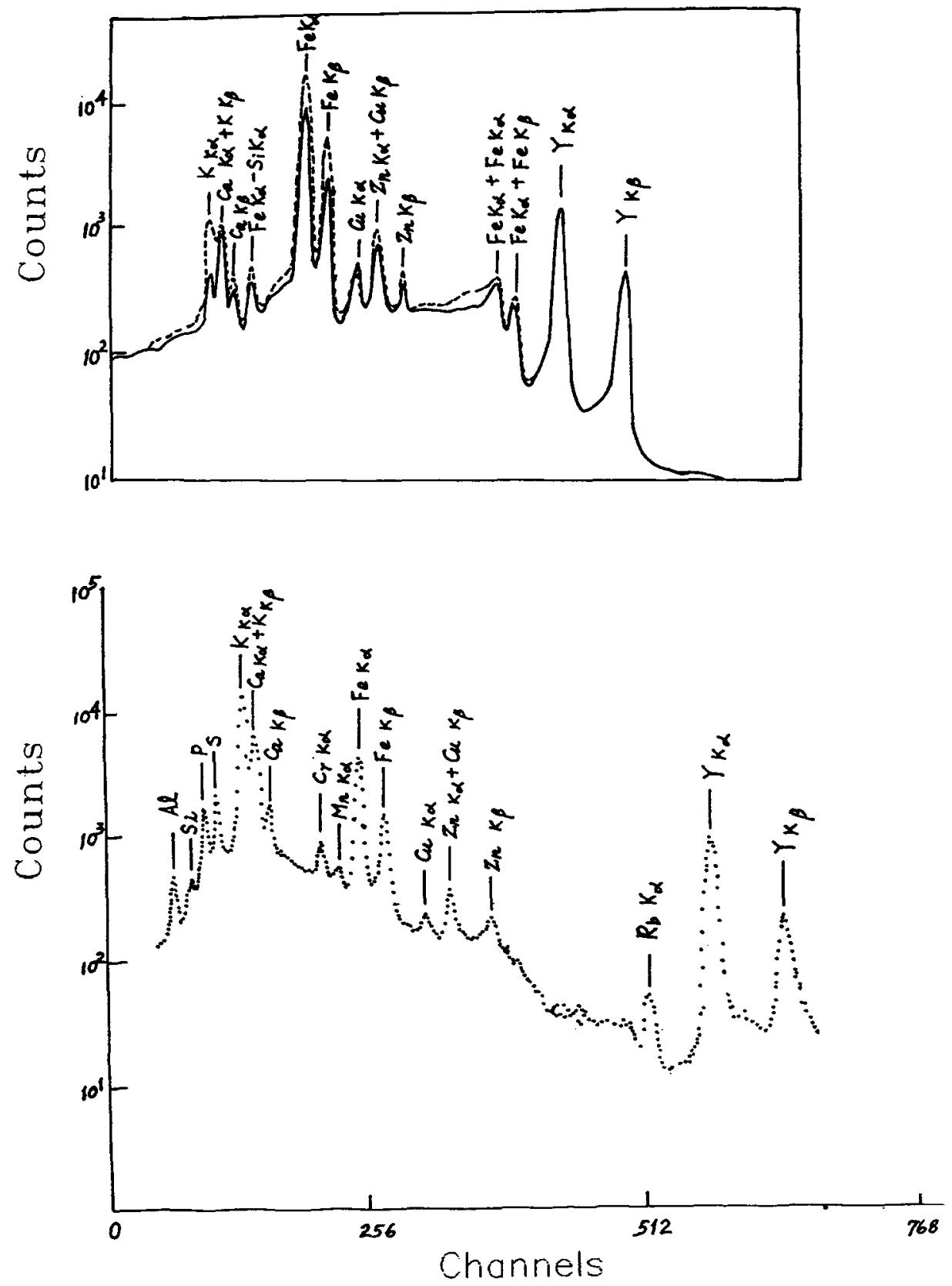

Fig. 1. The effect of a $\mathrm{Cr}$ absorber with thickness of $100 \mu \mathrm{m}$ on the PIXE spectrum of whole blood.

contents of elements $\mathrm{Si}, \mathrm{P}, \mathrm{S}, \mathrm{Ca}, \mathrm{Cu}$ and the ratio of $\mathrm{Cu}$ to $\mathrm{Zn}(\mathrm{Cu} / \mathrm{Zn})$ were higher and those of elements $\mathrm{Al}, \mathrm{K}, \mathrm{Fe}$, $\mathrm{Zn}$ and $\mathrm{Rb}$ were lower with high significant differences $(P<0.01)$ in acute leukemia patients than those in normal controls. The results indicated that the contents of $\mathrm{Cu}, \mathrm{Zn}$ and the ratio $\mathrm{Cu} / \mathrm{Zn}$ are useful indices of clinical symptoms. The elements of $\mathrm{Al}$ and $\mathrm{Rb}$ may play important roles in acute leukemia etiology.

\subsection{PIXE analysis of bone samples}

In recent years some attention has been paid to the analysis of bone and calcified samples. The bone such as skeleton, besides its obvious supporting function, is also a reservoir of essential and toxic elements. Its inorganic component is mainly hydroxyapatite $\left(\mathrm{Ca}_{10}\left(\mathrm{PO}_{4}\right)_{6}(\mathrm{OH})_{2}\right)$ with chemical components of $\mathrm{Ca} 39.9 \%, \mathrm{P} 18.5 \%$, 
$\mathrm{O} 41.4 \%, \mathrm{H} 0.2 \%$ in weight. $\mathrm{P}$ and $\mathrm{Ca}$ are the major elements in bone. It can be found in Fig. 2 that the major element $\mathrm{Ca}$ makes a serious interference in PIXE measurements with other trace elements in bone. There were several papers [6-8] dealing with the improvement of the PIXE spectra of bone samples using different absorbers. Various X-ray absorbers such as aluminum foil, polystyrene film, mica film and some kinds of combined absorbers were tested in our laboratory to suppress the intensity of $\mathrm{K} \alpha \mathrm{X}$-rays of $\mathrm{Ca}$ and therefore the influence of $\mathrm{Ca}$ to other trace elements in bone sample was greatly depressed. The best one of those absorbers is a kind of multi-layer combined sandwich absorber composed of 2 pieces of polyester film (each piece with a thickness of $\left.17.3 \mathrm{mg} / \mathrm{cm}^{2}\right)+$ mica film $\left(14.7 \mathrm{mg} / \mathrm{cm}^{2}\right)+2$ pieces of polyester film $\left(34.6 \mathrm{mg} / \mathrm{cm}^{2}\right)$. The peaks of trace elements of $\mathrm{V}, \mathrm{Cr}, \mathrm{Mn}, \mathrm{Fe}, \mathrm{Ni}, \mathrm{Cu}, \mathrm{Zn}$, and $\mathrm{Sr}$ were clearly shown in Fig. 2 using this sort of absorber. The process of bone fracture healing is influenced by many factors, especially by trace elements in organisms. The study of the changes of metal elements contents during fracture healing was carried out in our laboratory by PIXE. The radii of rabbits were fractured by operation and the content of $\mathrm{P}, \mathrm{Ca}, \mathrm{Cr}$, $\mathrm{Mn}, \mathrm{Fe}, \mathrm{Co}, \mathrm{Ni}, \mathrm{Cu}, \mathrm{Zn}$ and $\mathrm{Sr}$ in boe crusts during the healing period between the first to seventh week after fracture was determined. The results showed that the contents of all these analyzed elements were different from those in lateral contrast in the same rabbit. The content of $\mathrm{Ca}$ in the fractured position was nearly constant during healing period and that of other elements changed actively. The content alteration of the trace elements $\mathrm{Sr}$ and $\mathrm{Fe}$ during the healing period showed an interesting behavior. After operation the content of $\mathrm{Sr}$ decreased and then increased to the original level showing a concave shape. This alteration is consistent with the result by INAA [9]. On the contrary, after operation the content of Fe increased and then decreased to the original level showing a convex

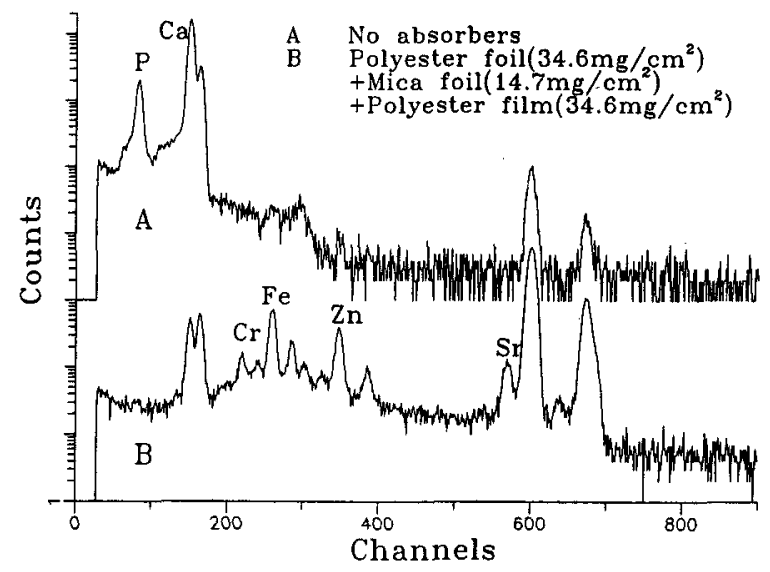

Fig. 2. The comparison of the PIXE spectra of the same bone sample with and without absorbers.

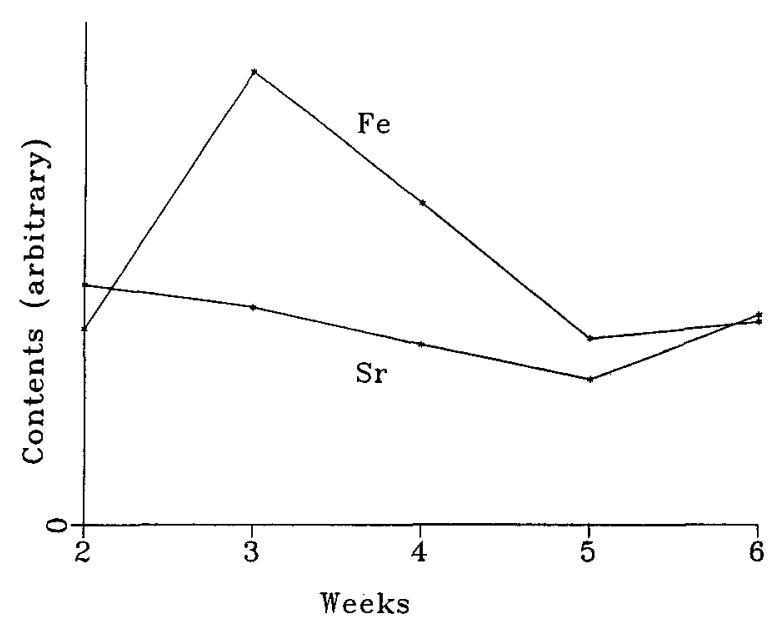

Fig. 3. The changes of the contents of elements $\mathrm{Sr}$ and $\mathrm{Fe}$ in bone in rabbits during fracture healing.

shape. For comparison the content of elements $\mathrm{Fe}$ and $\mathrm{Sr}$ was normalized to that of $\mathrm{Ca}$ and their alternations during fracture healing are shown in Fig. 3. All these results from the PIXE analysis of whole blood and bone samples imply that it is important to select certain elements in proper organs or body fluid as indicators for special disease. Our experimental results imply that it is promising to select the trace elements $\mathrm{Sr}$ and $\mathrm{Fe}$ in bone as two indicators for fracture healing.

\section{Single aerosol analysis by SPM}

\subsection{Motivation and idea}

Macro proton induced X-ray emission (macro PIXE) has been widely used in the analysis of the major, minor and trace element contents of atmospheric aerosol samples for the identification of air pollution sources and specially for the apportionment of the different aerosol sources [10]. It is valuable to determine the distribution of elemental contents versus aerosol size for air pollution [11,12]. Sometimes multivariate statistic analysis was used for the study of air pollution sources and their apportionment. This method (macro PIXE plus multivariate analysis technique) is widely accepted as a typical and standard routine mode by most of the analytical laboratories. The practice of scientific research work verifies that this method is quite efficient and was also used in our laboratory for studies on biological and environmental science $[12,20]$.

Single aerosol samples can be analyzed by means of electron probe X-ray micro analysis (EPXMA), laser mass miroanalysis (LAMMA) and scanning proton microprobe (SPM). Among these techniques SPM has much better 
sensitivity at ppm level and about 20-30 elements can be simultaneously detected. The penetration of protons with an energy of $4 \mathrm{MeV}$ is more than $20 \mu \mathrm{m}$ and therefore bulk information of single aerosol can be obtained. Proton microscope analysis (micro PIXE) of single aerosol particles has been developed recently as a new approach to the studies of air pollution [13,14]. Some papers [15-17] studied the spatial distribution of trace elements in individual fly ash particles by SPM. However, air pollution is contributed from various sources, for the environmental assessment sometimes many single aerosol partices (more than hundreds by SPM in Ref. [18] and even more than ten thousands by EPXMA in Ref. [19]) were analyzed quantitatively and multivariate statistical analysis was used for data handling process. Unfortunately this method (micro PIXE plus the multivariate analysis technique) is quite time consuming for the large amount of samples being analyzed and quite complicated for data handling. We try to use the knowledge of environmental science to look for a new method to simplify the analysis procedures. The basic idea is that a single aerosol can be considered statistically as a representative characteristic of a pollution source. According to the known facts of environmental science, some elements in aerosol could be considered as the representative characteristics of the special pollution sources. For example, aluminosilicate for soil dust, $\mathrm{Na}$ and $\mathrm{Cl}$ for marine aerosol, $\mathrm{Pb}$ and $\mathrm{Br}$ for the exhaust of vehicles, $\mathrm{S}$ and As for coal burning and other elements for anthropogenic sources especially for industrial pollution. Generally there are several sources for air pollution in one polluted area. Based on all these considerations in this context it is important to study the elemental distribution in a group of single aerosol particles (more then ten) on the environmental research for studying the sources of air pollution. This method could not be used in macro PIXE analysis for an aerosol sample because one aerosol sample consists of many single aerosol particles from different pollution sources and an aerosol sample could not be considered as a representative characteristic of a pollution source. This method is different from the conventional one of an single aerosol study, in which the distribution of elements inside a single aerosol is analyzed. A single aerosol particle is analyzed as a whole in our method. Therefore a primary study on a group of single aerosol particles for the identification of air pollution sources by means of SPM is introduced in the present report.

\subsection{Sample preparation for single aerosol particle}

Aerosol samples were collected at Bei Xin An village primary school, which is located between the Capital Steel Plant and the Capital Special Steel Plant, Shi Jing Shan district, Beijing from December 1993 to January 1994 using an Andersen cascade impact sampler (a product of Andersen Samlers, In., USA).

Several methods for preparing samples of dispersed single aerosol particles used in SPM analysis were tested. With some improvements with respect to the methods introduced in [15,21], two kinds of successful preparation of single particle samples were obtained. Another similar method developed in our laboratory was tested and the result shows that it seems better than the others. The procedure was the following:

a) A solution of Poly Vynilidene Florid powder (PVDF, $\left.\left(\mathrm{F}_{2} \mathrm{C}-\mathrm{CH}_{2}\right)_{n}\right)$ in $\mathrm{N}, \quad \mathrm{N}$-Dimethyl Formamide $\left(\mathrm{HCON}\left(\mathrm{CH}_{3}\right)_{2}\right)$ was prepared at the temperature of $80^{\circ} \mathrm{C}$.

b) The collected aerosol particles were dropped into the solution with the aid of shaking and stirring to form aerosol particle suspension solution.

c) $10 \mu \mathrm{l}$ of the aerosol particle - PVDF - N,N Dimethyl Formamide solution was dropped onto a $3 \mu \mathrm{m}$ thick Mylar film fixed on a stainless steel frame.

d) The resulting PVDF-Mylar film was baked at the temperature of $120^{\circ} \mathrm{C}$ for two hours. The film was stretched taut and quite flat with the dispersed single aerosol particles embedded in it.

The aerosol particles were not resolved by the used organic chemical solvents as confirmed in the SPM spectrum of a group of single aerosol particles shown in Fig. 4, where a clear boundary of the single particles shows up and nothing can be seen in the background area.

\subsection{Experimental}

The SPM [22] with long focus in Shanghai Institute of Nuclear Research, Academia Sinica was used in the present work. It was operated with $5 \mu \mathrm{m}$ spatial resolution at $100 \mathrm{pA}$ beam current with energy of $4 \mathrm{MeV}$. The advanced modes of the fast random scan and the event by event data collection made it possible to treat the multiparameter and multi-detector data through the Total Quantitative Scanning Analysis (TQSA). A three dimensional display with isometric and contour plots was provided.

The aerosol samples with a nominal aerodynamic diameter of 7-11 $\mu \mathrm{m}$ (colleted at the first stage of the Andersen cascade sampler) were analyzed. Three scanning regions, each $180 \mu \mathrm{m} \times 150 \mu \mathrm{m}$ in size, were selected for analysis. The selected spatial resolution of $5 \mu \mathrm{m}$ of the proton beam was somewhat less than the nominal aerodynamic diameter of the single aerosol particles to avoid the proton beam bombarding on more than one aerosol particle simultaneously. The number of single particles in each scanning region was more than ten and all these particles compose a group. The particles in each scanning region were verified by an optical microscope to make sure that all single particles were well separated from each other.

\subsection{Results and discussion}

The similar distributions of more than ten elements such as $\mathrm{Al}, \mathrm{Si}, \mathrm{S}, \mathrm{Cl}, \mathrm{Ca}, \mathrm{Mn}, \mathrm{Fe}, \mathrm{Ni}, \mathrm{Cu}$ and $\mathrm{Zn}$ in three selected scanning regions were obtained and the distribu- 


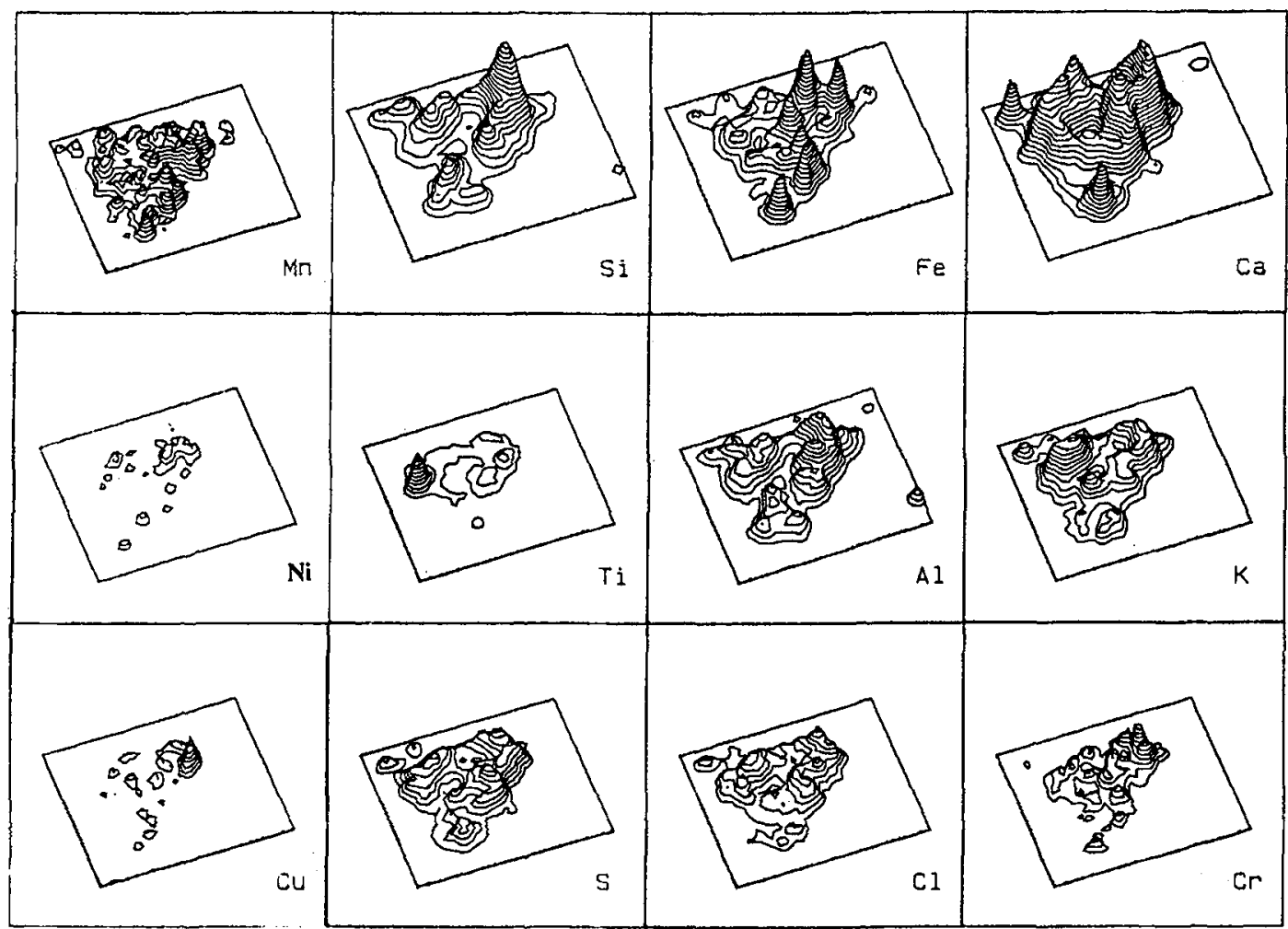

Fig. 4. Distribution maps of elements in a group of different single particles in the scanning region $180 \mu \mathrm{m} \times 150 \mu \mathrm{m}$.

tions of those elements in a group of single particles are shown in Fig. 4, where the distributions are mapped with three dimensional contour and isometric.

The air pollution in the Capital Steel Plant area was studied several years ago [23], so the air pollution sources and their apportionment were known. The main sources to the air pollution in this area were soil dust, coal combustion during heating season and waste products of the industry from the steel plant. We evaluated the feasibility of studying the air pollution sources by SPM analysis in a group of single aerosol particles.

The distributions of elements of $\mathrm{Al}, \mathrm{Si}, \mathrm{S}, \mathrm{Ca}$ and $\mathrm{Cl}$ in the group are in similar patterns. The distribution of silicon in the group has the same pattern as that of aluminum, which implies that there are silicon and aluminium compounds in the particles. On the other hand, as the contents of silicon are much higher than that of the aluminum, this compound must be aluminosilicate originated mostly from the soil dust and often appears in air pollution. The content of $S$ being quite high compared with other elements, the contributor of sulfor is mainly related to coal combustion during the heating season [23].

Since the distribution of calcium in the group of single aerosol particles is similar to that of sulfur, these two elements should coexist in the same chemical compound, possibly calcium sulfate $\left(\mathrm{CaSO}_{4}\right)$. Moreover the distribution of calcium is similar to that of some metal elements such as $\mathrm{Cr}, \mathrm{Mn}, \mathrm{Fe}, \mathrm{Ni}$ and $\mathrm{Zn}$. It means the coexistance of $\mathrm{Ca}, \mathrm{Cr}, \mathrm{Mn}, \mathrm{Fe}, \mathrm{Ni}$ and $\mathrm{Zn}$ in the same particles from the steel plant. A possible explanation of this phenomenon is that the basic process is often used in the steel plant and iron mill. It is resonable that all these elements coexist in some particles. Fig. 4 shows that the distributions of metal elements $\mathrm{Fe}, \mathrm{Cr}, \mathrm{Mn}, \mathrm{Ni}$ and $\mathrm{Zn}$ in the group of single aerosol particles are also in similar patterns. This phenomenon can be explained as follows: various black metal materials (e.g. carbon steel, carbon tool steel, carbon structural steel, spring steel, bearing steel, cast steel, cast iron) and many other iron and steel products can be produced in the Capital Steel Plant. The elements such as $\mathrm{Mn}, \mathrm{Cr}, \mathrm{Ni}, \mathrm{Zn}, \mathrm{Fe}, \mathrm{P}$ and $\mathrm{S}$ are the elemental components of these metal materials. All these elements are contributed to the air pollution in the production process in the steel plant.

In conclusion, the distributions of elements in the group of single aerosol particles indicate the representative characteristics of the air pollution sources in the steel plant area. The main contributors to the air pollution in this area are soil dust, coal combustion during heating season and waste products of the industry from the steel plant. This conclusion is the same as that made several years ago [23]. It is evident that the SPM study on a group of single aerosol particles is effective in solving the environmental problems, especially in the study of air pollution sources 
qualitatively. It is promising to explore this approach to study the species of aerosol particles with the quantitative nuclear microprobe analytical technique.

\section{References}

[1] C.V. Mathai, J. Air Waste Manage. Assoc. 40 (1990) 1486.

[2] Xianzhou Zeng, Huiying Yao, Yongnian Sun, Xiankang Wu and Fujia Yang, Int. J. PIXE 1(1) (1990) 43.

[3] Lu Ying, Luo Daopei and Wang Liangxu, Chin. J. Hematology 7(1) (1986) 28.

[4] Sha Yin, Liu Pingsheng, Zhang Peiqun, Liu Guodong, Lin Han, Yang Bing and Qian Linsheng, Int. J. PIXE 2(4) (1992) 569.

[5] Sha Yin, Liu Pinsheng, Zhang Peiqun, Liu Guodong, Lin Han, Yang Bing and Qian Lingsheng. Analytical Laboratory 12(3) (1993) 7, in Chinese.

[6] Y. Nishide, E. Hayashi, K. Maeda. Y. Sasa and M. Uda, Nucl. Instr. and Meth. B 75 (1993) 200.

[7] C.P. Swann, Nucl. Instr. and Meth. 197 (1982) 237.

[8] M. Jaksic, S. Fazinic, J. Krmpotic-Nemanic, M. Budnar, Z. Smit and V. Valkovic, Nucl. Instr. and Meth. B 22 (1987) 193.

[9] Qinfang Qian, Shaojin Yang, Yinan Yang, Bingru Chen, Guodong Liu, Han Lin, Wenzheng Lan, Xiaoheng Wen, Genyuan Ji and Shusheng Ma, J. Radioanal. Nucl. Chem., Lett. 127(4) (1988) 275.

[10] T.A. Cahill, Nucl. Instr. and Meth. B 49 (1990) 345.

[11] W. Maenhaut, Int. J. PIXE 2(4) (1992) 609.
[12] Sha Yin, Liu Pingsheng, Hu Zhaohui, Zhong Ming, Yang Shaojin, Yang Yinan, Qian Qinfang and Chen Binru, Int. J. PIXE 2(4) (1992) 593.

[13] E. Swieticki, G. Lovestam and U. Watjen, J. Aerosol Sci. 21 (suppl. 1) (1990) S605.

[14] P. Artaxo, R. Van Grieken, F. Watt and M. Jaksic, Proc. 2nd World Congr. on Particle Technology, Kyoto, Japan, 1990, p. 421.

[15] M. Jaksic, F. Watt, G.W. Grime, E. Cereda, G.M. Braga Marcazzan and V. Valkovic, Nucl. Instr. and Meth. B 56/57 (1991) 699 .

[16] B. Bellagamba, A. Caridi, E. Cereda, G.M. Braga Marcazzan and V. Valkovic, Nucl. Instr. and Meth. B 75 (1993) 222.

[17] M. Jaksic, I. Bogdanovic, E. Cereda, S. Fazinic and V. Valkovic, Nucl. Instr. and Meth. B 77 (1993) 505.

[18] I. Orlic, T. Osipowicz, F. Watt and S.M. Tang, Proc. 4th Int. Conf. on Nuclear Microprobe Technology and Applications, Shanghai, China, 1994, Nucl. Instr. and Meth. B 104 (1995) 630 .

[19] C. Xhoffer, P. Bernard, R. van Grieken and L. van der Auwera, Environ. Sci. 25 (1991) 1470.

[20] Sha Yin, Liu Pingsheng, Dong Yulan, Zhang Peiqun, Yang Zhengjun, Wu Yue, Li Jingxiu, Liu Dexiang, Wang Yukun and Zhang Dekang, Nucl. Instr. and Meth. B 75 (1993) 177.

[21] F.A.J. de Rooij, H.P.M. Kivits, C.A.M. Castelijns, G.P.J. Wijnhven and J.J.M. de Goeij, Nucl. Instr. and Meth. 181 (1981) 63.

[22] Zhu Jieqing, Li Mingqian, Mao Yu, Chen Hanmin, Gu Yingmei, Yang Changyi and Sheng Kanglong, Nucl. Techniques 14(9) (1991) 525, in Chinese.

[23] Wang Anpu and Yang Shulan, Chin. J. Environmental Sci. $5(2)$ (1984) 14, in Chinese. 